\title{
Negative view of the self and symptoms of depression in adolescents
}

\section{Article}

\section{Accepted Version}

Creative Commons: Attribution-Noncommercial-No Derivative Works 4.0

Hards, E., Ellis, J., Fisk, J. and Reynolds, S. (2020) Negative view of the self and symptoms of depression in adolescents. Journal of Affective Disorders, 262. pp. 143-148. ISSN 01650327 doi: https://doi.org/10.1016/j.jad.2019.11.012 Available at https://centaur.reading.ac.uk/87166/

It is advisable to refer to the publisher's version if you intend to cite from the work. See Guidance on citing.

To link to this article DOI: http://dx.doi.org/10.1016/j.jad.2019.11.012

Publisher: Elsevier

All outputs in CentAUR are protected by Intellectual Property Rights law, including copyright law. Copyright and IPR is retained by the creators or other copyright holders. Terms and conditions for use of this material are defined in the End User Agreement.

\section{www.reading.ac.uk/centaur}

\section{CentAUR}

Central Archive at the University of Reading

Reading's research outputs online 


\section{Journal Pre-proof}

Negative view of the self and symptoms of depression in adolescents

Emily Hards ConceptulisationData collectionData codingFormal analysisWriting the original draft , Judi Ellis Writing - review and editing , Jennifer Fisk Data collection and Data coding ,

Shirley Reynolds ConceptualisationWriting - review and editing

PII:

DOI:

S0165-0327(19)31486-7

Reference:

https://doi.org/10.1016/j.jad.2019.11.012

JOURNAL of

AFFECTIVE DISORDERS

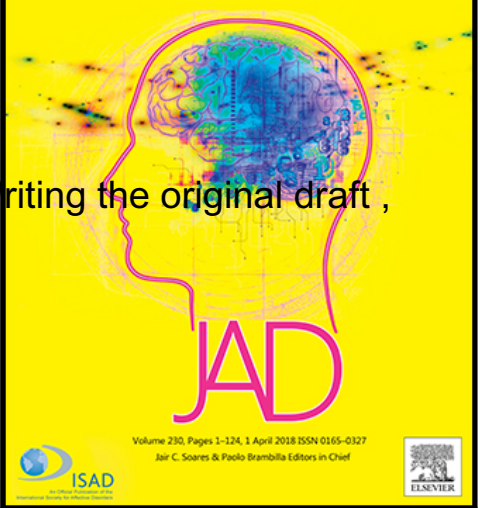

To appear in:

Journal of Affective Disorders

Received date:

5 June 2019

Revised date:

11 October 2019

Accepted date:

2 November 2019

Please cite this article as: Emily Hards ConceptulisationData collectionData codingFormal analysisWriting the origir Judi Ellis Writing - review and editing , Jennifer Fisk Data collection and Data coding, Shirley Reynolds ConceptualisationWriting - review and editing, Negative view of the self and symptoms of depression in adolescents, Journal of Affective Disorders (2019), doi: https://doi.org/10.1016/j.jad.2019.11.012

This is a PDF file of an article that has undergone enhancements after acceptance, such as the addition of a cover page and metadata, and formatting for readability, but it is not yet the definitive version of record. This version will undergo additional copyediting, typesetting and review before it is published in its final form, but we are providing this version to give early visibility of the article. Please note that, during the production process, errors may be discovered which could affect the content, and all legal disclaimers that apply to the journal pertain.

(C) 2019 Published by Elsevier B.V. 


\section{Highlights}

- In a large sample of young people aged 13-18 years self-evaluation was significantly correlated with depression symptoms.

- Self-complexity was not associated with the severity of depression.

- Negative self-evaluation may constitute a risk factor for depression in young people and thus might be a target for prevention and early intervention 


\section{Negative view of the self and symptoms of depression in adolescents}

\section{Emily Hards $^{1 *}$, Judi Ellis ${ }^{1}$, Jennifer Fisk ${ }^{1}$, Shirley Reynolds ${ }^{1}$}

${ }^{1}$ School of Psychology and Clinical Language Sciences, University of Reading, Earley Gate, Whiteknights Road, Reading, RG6 6AL, United Kingdom

\section{* Correspondence:}

Emily Hards

Emily.Hards@ reading.ac.uk

Declaration of Interest: None Abstract

Background. Although negative self-evaluation is a common symptom of depression in adolescents, there is little understanding of how the self is associated with depression. Beck (1967) proposed that a negative view of the self was a 'hallmark' of depression. In contrast Linville $(1985 ; 1987)$ proposed that holding multiple aspects of the self was associated with lower levels of depression. The aim of this paper is to evaluate these two models of self and depression in adolescents.

Methods. Young people aged 13-18 years $(n=822)$ reported symptoms of depression (the Mood and Feelings Questionnaire) and completed a measure of self-concept, the Twenty Statements Test (TST). We coded responses to the TST to reflect the valance (positive to negative) and the complexity of their self-concept (number of self-aspects).

Results. Valence, but not complexity, of self-concept was significantly associated with severity of depression symptoms. The valance of young people's self-concept accounted for $25 \%$ of the variance in depression symptoms. Adolescent's with more positive self-concept tended to have fewer symptoms of depression. 
Limitations. The cross-sectional design of this study precludes any conclusions about the causal relationship between depression and negative self-evaluation; experimental and longitudinal research is needed to assess the causal direction of the relationship.Conclusions. The results of this study supported the cognitive model of depression. Negative selfevaluation may constitute a risk factor for depression in adolescents and could offer a potential target for prevention and early intervention in adolescents.

Key words: adolescence; depression; cognitive theory; self-complexity; self-evaluation

\section{Authorship Contribution Statements}

EH: Conceptulisation, Data collection, Data coding, Formal analysis, Writing the original draft. JE: Writing - review and editing. Jennifer Fisk: Data collection and Data coding. SR: Conceptualisation, Writing - review and editing.

Key words: adolescence; depression; cognitive theory; self-complexity; self-evaluation 


\section{Introduction}

Adolescence is an important period for the development of the self. It represents a time of increasing self-exploration (Erikson, 1968). Once consolidated, an adolescent self concept is suggested to have an enduring effect across the lifespan. For example, important perceptions of 'the self' developed during adolescence are associated with self-defining memories (Singer \& Salovey, 1993) and remain highly accessible across the lifespan (Conway, 2005). The self-concept has also been identified as a potential key factor in the development and maintenance of mood disorders. Beck (1967) proposed that depression was characterised by the 'Cognitive Triad', consisting of negative beliefs about the self, the world and the future. He suggested that a pervasively negative view of the self acts as a cognitive vulnerability for depression. In contrast, Linville $(1985,1987)$ proposed that depression is associated with the way in which the self is structured. She hypothesised that having more distinct (i.e. non overlapping) aspects of the self increased resilience to adverse life events and protected people against depression. Conversely, fewer and overlapping aspects of the self increased vulnerability to adverse life events and the risk of depression.

Adolescence is a life stage when individuals are highly vulnerable to the onset of mental health problems. Depression is strikingly common during this period with an estimated point prevalence of 2.7 - 4.8\% for young people aged 13 to 18 years (NHS Digital, 2018). Depression during adolescence increases the risk of developing other mental health disorders in adulthood (Fergusson, Horwood, Ridder, \& Beautrais, 2005), and of suicide, poor physical health and self-harm (Stanley et al., 2017; Zubrick et al., 2017).

Understanding more about the content, structure and valence of the self-concept at this critical period of development may help prevent or treat adolescent depression. For example, if having a negative self-concept is causally related to the development of depression in adolescents, improving positive self-concept and reducing negative self-concept 
may help to prevent the onset of depression. Similarly, if self-complexity is causally related to depression then strategies to help increase self-complexity may be beneficial. Likewise, if negative self-concept or low self-complexity maintain depression, interventions to target these could be incorporated into psychological treatments.

Negative self-evaluation is one of the 10 symptoms that are part of the diagnostic criteria for depression in adolescents (DSM 5, APA, 2013) and is one of the most frequently observed symptoms of depression in young people (Orchard, Pass, Marshall, \& Reynolds, 2017). Emerging evidence suggests that negative self evalution may also predict the severity of depression and depression diagnostic status in young people (Orchard \& Reynolds, 2018). The relationship between self-evaluation and depression has been examined from different perspectives. Some research has examined 'negative self-referential processing'. This refers to the tendency of depressed individuals to attribute negative traits and characteristics to themselves (Lemogne et al., 2010). This has frequently been demonstrated to be a cognitive bias in young people with depression. For example, depressed adolescents endorsed more negative and fewer positive adjectives as self-referent (i.e., related to 'me') than healthy controls (Auerbach, Stanton, Proudfit, \& Pizzagalli, 2015). Young people with elevated depression symptoms also endorsed negative adjectives more quickly, and positive adjectives more slowly, than adolescents who reported fewer symptoms of depression (Connolly, Abramson, \& Alloy, 2016). There is some evidence of a causal relationship between selfevaluation and negative mood. After a negative mood induction adolescents endorsed significantly more negative self-descriptions than after a neutral mood induction (Kelvin, Goodyer, Teasdale \& Brechin; 1999). The related concept of self-esteem - a global representation of self-concept - has also been examined in adolescents using longitudinal and experimental designs. Low self-esteem (i.e., a more negative view of the self) is strongly associated with depression and predicts future depression symptoms (Orth, Robins, Widaman 
\& Conger, 2014; Steiger, Allemand, Robins \& Fend, 2014). A bias towards negative selfevaluation is also hypothesised to increase attention to other negative self-referent information in the form of brooding and thus to amplify and increase the symptoms of depression (Black \& Pössel, 2013).

The structure of the self is typically believed to include multiple aspects of the self (Neisser, 1991; Oyserman, Elmore \& Smith, 2012). These include 'Traits' (e.g., "I am funny”), 'Active roles' (e.g., "I am a footballer”), 'Aspirations' (e.g., "I am hoping to go to university”), and 'Family relationships' (e.g., "I am a daughter”; Oyserman, Elmore \& Smith, 2012). Linville $(1985 ; 1987)$ proposed that when an individual experiences an aversive event (e.g., failing an exam) the self-aspect most closely related to the event is activated (e.g., the self in academic contexts). Negative self-images relating to that self-aspect then come to mind (e.g., "I am a bad student", "I will fail all my exams"). Linville suggested that individuals with fewer self-aspects and greater overlap (or similarity) between aspects are more likely to experience low mood or depression in response to an adverse event because a negative event would activate a larger proportion of their self-aspects and fewer self-aspects would be unaffected. Therefore, self-complexity theory predicts that a more complex 'self' with multiple different aspects protects individuals from depression because it buffers them against the negative impact of adverse events.

Research testing self-complexity theory has primarily focused on adults (see RafaeliMora \& Steinberg, 2002; Linville, 1985, 1987). There has been relatively little research testing the self-complexity theory of depression in young people (Linville, 1985, 1087). We identified four studies of self-complexity and depression in adolescents. Evans (1994) reported that self-complexity was significantly negatively correlated with depression symptoms. However, Jordan \& Cole (1996) reported that higher self-complexity was associated with depression in young people aged 9-14 years, i.e., a positive correlation 
between self-complexity and depression. Two prospective studies have reported that selfcomplexity did not predict future depression. The number of self-aspects in children aged 9 to 13 years, did not predict depression symptoms ten weeks later (Abela \& VéronneauMcArdle, 2002). Similarly Cohen, Spiegler, Young, Hankin, and Abela (2014) assessed selfcomplexity and depression in young adolescents (mean age 12 years) every three months during a period of two years. They concluded that the number of self-aspects did not predict later depression symptoms, and that less overlap of self-aspects predicted increased depression symptoms.

Methods of measuring self-concept are varied. Some researchers use prepopulated or standard sets of descriptions that they ask respondents to endorse (or not). For example Kelvin, Goodyer, Teasdale, and Brechin (1999) developed the Self-Description Questionnaire (SDQ): a 30- item questionnaire that includes 12 positive, 12 negative and 6 neutral adjectives. On the SDQ, participants are asked to indicate to what extent each adjective describes them ('Not at all like me', 'A bit like me', 'A lot like me', 'Very much like me'). An alternative method of eliciting self-concept is to invite participants to generate their own self-descriptions. This allows individuals to use more personal, and possibly more salient descriptions. These may also be more sensitive to individual or group differences, including those related to cohort membership, age, gender and other demographic factors (McGuire, McGuire, Child, \& Fujioka, 1978; McGuire \& Padawer-Singer, 1976). In the current study we used an open-response measure, the Twenty Statements Test (TST; Kuhn \& McPartland, 1954), to elicit participants' self-concept. The TST asks participants to response to the question, 'Who am I?' by completing up to 20 sentence stems, each beginning 'I am...'.

The aim of the current study is to test two hypotheses arising from contrasting theories of the relationship between the self and depression in adolescents. The first hypothesis, based on Beck's cognitive theory of depression, is that valance of self-concept is negatively 
correlated with depression. The second hypothesis, based on Linville's self-complexity theory, is that complexity of self-concept is negatively correlated severity of depression symptoms. We will also examine which index of 'self' (i.e. self-evaluation or selfcomplexity) is the stronger predictor of depression severity in young people.

\section{Materials and methods}

\subsection{Materials}

Depression symptoms were measured by the Mood and Feelings Questionnaire (MFQ; Costello \& Angold, 1988). The MFQ is a 33-item self-report questionnaire measure of adolescent depression symptoms. Respondents are asked to rate each item on a 3-point Likert scale from 0 (not true) to 2 (true). Higher MFQ scores indicate more severe symptoms

of depression (Goodyer et al., 2017; Wood, Kroll, Moore, \& Harrington, 1995). A score of 27 or over on the MFQ is considered to indicate that a young person is at risk of depression (Wood et al., 1995). The MFQ has good internal consistency $(\alpha=.94$, ) and good construct validity and diagnostic accuracy in adolescents (Wood et al., 1995).

Self-concept was assessed by the Twenty Statements Test (TST; Kuhn \& McPartland, 1954). This provides 20 unfinished statements beginning with the phrase "I am...". Participants are asked to define themselves by responding to the question "Who am I?" by completing as many statements as possible. Young people were asked not to think too much about their answers, or to worry about the order of their responses. They were not given examples of responses and were told that they could include any way of defining themselves that they felt were important. Following this, a sub-sample of participants all attending one of the three schools ( $n=258$ ) were asked to circle up to three self-images that were the most important to them and best defined them as a person. These data was analysed as part of another research study.

\subsubsection{Classification of self-images}


The self-images obtained using the TST reported in this paper here are freely accessible in the UK Data Service ReShare Repository under 'XXX' (Author(s) details) at Website link. DOI: XX).

TST responses were coded using a scheme developed by Hards, Ellis, Fisk \& Reynolds (submitted). There were 12 categories of self; 'Active roles', 'Hobbies and interests', 'Core identity', 'Traits', 'Demographics', 'Family relationships', 'Physical appearance', 'Emotional self-reflection', 'Academic self', 'I am unique', 'Aspirations', and 'Peer relationships'. Interrater reliability was assessed on a sub-sample of $10 \%$ of the data by two authors (XX and XY) coding responses independently and blind to participant MFQ, gender and age. Interrater reliability was good between researchers $(84.6 \%$ agreement, $\kappa=0.80)$. All self-images were then coded independently by the first author (XX) who was blind to participants' MFQ score, gender and age.

Self-complexity. The number of separate aspects of "the self" that were generated by each participant was used as an index of self-complexity.

Valence of the self. The valance of each self-image was coded as positive, (e.g. "I am happy"), neutral, (e.g. "I am shy"), or negative (e.g. "I am depressed"). Only self-images that were explicitly valenced were included in this analysis. Other self-images (e.g., that described social roles) were removed. Two authors, blind to MFQ score, gender and age of participants coded the valence of each statement. Inter-rater reliability was excellent $(96.5 \%, \kappa=.94)$. Following this, associations between depression symptoms (MFQ score) and the proportion of positive, neutral and negative self-images was calculated using Pearson's correlation analyses. The proportion of positive self-images generated by each participants was negatively associated with depression severity $(r=-.51, p<.00195 \% \mathrm{BCa} \mathrm{Cl}[-.59,-.46$ and the proportion of negative self-images was positively associated with depression severity $r=$ $.52, p<.001,95 \% \mathrm{BCa} \mathrm{Cl}[.43, .55]$. Neutral self-images were not significantly associated 
with depression symptoms $(r=.07, p=.05,95 \% \mathrm{BCa} \mathrm{Cl}[-.01, .13]$. Therefore, the SelfValence Index (SVI) was calculated by the difference between the proportion of positive and negative self-images, plus one (to ensure all values were positive). Neutral self-images were not included in the SVI. The range of the SVI was from 0 , indicating a fully negative selfevaluation to 2 , indicating, a fully positive self-evaluation).

\subsection{Subjects}

Young people $(n=1688)$ attending three publicly funded secondary schools in the UK were invited to take part in the study. Consent was obtained from 919 young people $(54.4 \%)$ and complete data was obtained from 822 young people aged 13 to 18 years $(48.7 \%$ of those invited). The mean age of participants was 14.85 years, $(\mathrm{SD}=1.35) ; 54.7 \%$ were female and $85.2 \%$ were of White British ethnicity. Twenty two percent of young people in the sample scored above the clinical cut off of 27 for depression on the MFQ; $13.7 \%$ of boys and $28.2 \%$ of girls.

\subsection{Procedure}

To gain access to schools headteachers were sent information describing the study. If they expressed interest in taking part, the first author discussed the study aims and procedures with them in a face-to-face meeting. Following approval from headteachers, information sheets describing the study were distributed to all students aged 13 to 18 years and to their parents. Parents of young people under 16 years were required to provide consent via an optout method. If parents did not want their child to take part, they were asked to contact researchers via email, telephone/text, or written forms returned to the school. Their son or daughter was also required to provide written assent and was told that they did not have to take part if they did not want to. All adolescents over 16 provided written informed consent.

This study was approved by the University of XXX Ethics Committee. Participants completed measures in class ( $n$ approximately 30 ) in the presence of a researcher during 
timetabled tutorial time or Personal, Social, Health Education (PSHE) classes. The MFQ was completed first followed by the TST. Adolescents for whom consent/assent was not obtained, or who did not want to take part were given an alternative activity. Participants were entered into a prize draw in which 10 young people per school had the chance to win a $£ 10$ amazon voucher.

\section{Results}

\subsection{Analyses}

Data from 53 young people was excluded from the analysis as they did not generate any self-images that could be coded as positive or negative. Preliminary analyses were performed to assess any violations of assumptions. Self-complexity and MFQ scores were positively skewed and the SVI was negatively skewed so bootstrapping was used in all analyses (Field, 2013).

In the primary analysis we examined gender and age differences in each of the dependent variables. First we assessed depression symptoms. The mean MFQ score of participants included in the study was $17.10(\mathrm{SD}=12.73$; Range, $0-66)$. An independent ttest showed that females $(M=20.16, S D=13.37)$ had a higher MFQ score than males $(M=$ 13.31, $\mathrm{SD}=10.76, t(767)=7.69, p=.001,95 \% \mathrm{BCa} \mathrm{Cl}[-8.56,-5.21], d=0.6$. To assess the association between age and depression symptoms a pearson's correlation was perfomed. Participant age was not associated with severity of depression (see Table 1). Next we examined the number of self-images generated by young people using the TST. On average, adolescents generated $8.38(\mathrm{SD}=4.64)$ self-images. Results of an independent t-test showed that boys $(\mathrm{M}=7.54, \mathrm{SD}=4.35)$ generated significantly fewer self-images than girls $(\mathrm{M}=$ 9.05, $\mathrm{SD}=4.76 ; t(767)=4.52, p<.001,95 \% \mathrm{BCa} \mathrm{Cl}[-2.15,-.85], d=0.33)$. A Pearson's correlation indicated that age was not related to the number of self-images generated $(r=$ $.001,95 \% \mathrm{BCa} \mathrm{Cl}[.04,-.06], p=.97)$. Third, we examined gender and age differences in 
self-complexity and the SVI of young people. On average, adolescents generated 3.34 selfaspects $(\mathrm{SD}=1.73)$; an independent t-test showed that girls generated more self-aspects than boys $(\mathrm{M}=3.60, \mathrm{SD}=1.77 ; \mathrm{M}=3.04, \mathrm{SD}=1.62$ respectively $), t(767)=4.57, p=.001,95 \%$ $\mathrm{BCa} \mathrm{Cl}[-.81,-.32], d=0.3$. Pearson's correlation analysis showed that age was not signifcantly correlated with self-complexity (see Table 1). The mean SVI score was 1.30 (SD $=.61$ ), indicating a positively valenced self. On average self-concept of girls was more negative than self concept of boys, (girls $\mathrm{M}=1.24, \mathrm{SD}=.71$; boys $\mathrm{M}=1.48, \mathrm{SD}=.62$,) this difference was significant as highlighted by an independent samples t-test $(t(767)=4.89, p=$ $.001,95 \% \mathrm{BCa} \mathrm{Cl}[.14, .32], d=0.4$. Age was not significantly correlated with the SVI (see Table 1).

\subsection{Results}

\subsubsection{Correlations with depression symptoms}

We examined correlations between self-valance, self-complexity and depression symptoms (see Table 1) using pearson's correlations. There was a significant negative correlation between SVI (self-evaluation) and depression severity; adolescents who generated a more negative evaluation of the self endorsed more symptoms of depression. The relationship between self-complexity and severity of depression was also significant. There was a small positive correlation between self-complexity and severity of depression indicating that adolescents who generated more aspects of the self, endorsed more symptoms of depression. The two indices of 'self' were also negatively correlated; this indicates that a more negative self-evaluation was associated with greater self-complexity (i.e., more aspects of self).

\subsubsection{Self-complexity and Self-Valence Index (SVI) as predictors of depression}

We used a hierarchical multiple regression to assess which of the two indices of self, self-evaluation or self-complexity, was the stronger independent predictor of depression. All 
assumptions were met apart from normality, however given the large sample size a linear regression was deemed appropriate. As age was not associated with MFQ scores this was not entered into the model. Gender was entered as the first variable, $F(1,766)=58.59, p<.001$ and accounted for $7.1 \%$ of the variance in depression symptoms. Adding the Self-Valence Index $(\mathrm{SVI})$ was significant, $F(1,765)=287.62, p<.001$. The beta value $(\beta=-.51, p<.001)$ suggests that elevated depression symptoms were predicted by a more negative selfevaluation. Adding Self-complexity was not significant $F(3,764)=.25, p=.615 ; \beta=-.02$. In the final model Gender and Self-Valence Index (SVI) were independent predictors of depression symptoms and explained $32.3 \%$ of the variance in depression symptoms

\section{INSERT TABLE $1 \& 2$}

\section{Discussion}

Adolescence is a critical period of development that sets a trajectory for well-being, aspirations, relationships and cognitions, emotions and behaviours throughout life. Our concept of 'who we are', i.e., 'our self' becomes consolidated during adolescence and early adulthood and is influenced by life events, including any experience we might have of common mental health problems, including depression. These often emerge for the first time during adolescence and cause significant impairment in functioning. Self-concept and depression are directly linked through the inclusion of negative self-evaluation as a symptom of major depressive disorder (DSM 5, APA, 2013) but the relationship between the development of depression and the development of self-concept is largely unexplored. The cognitive model of depression (Beck, 1967) and self-complexity theory (Linville, 1985, 1987) predict that the self is associated with depression in different ways. This is the first study to evaluate two distinct accounts of the relationship between self-concept and depression in adolescents. As there is limited and conflicting evidence to support either 
theory in respect to adolescent depression, we tested each model in a sample of young people aged 13-18 years.

Our results supported the cognitive theory of depression, i.e., there was a positive correlation between self-evaluation and depression symptoms. There was a weak association between self-complexity and depression, but this was in the direction opposite to the hypothesis, i.e. more complexity was associated with higher depression. This is therefore contrary to the model of self-complexity proposed by Linville $(1985 ; 1987)$. In addition, only self-evaluation made an independent contribution to the prediction of depression severity. There was also a negative correlation between self-evaluation and self-complexity, suggesting that young people with a negative self-evaluation may have a more differentiated self-concept.

The results of this study have several important theoretical and clinical implications. Firstly, they suggest that a pervasively negative self is related to the severity of depression symptoms in a large community sample of young people. However, these results are based on self-report questionnaire measures of depression. The design was cross sectional and therefore we cannot make any inferences about the nature or direction of causality - it is quite possible that self-evaluation becomes more negative after depression symptoms emerge and / or that negative self-evaluation is a causal factor in the development of depression symptoms. Thus, future research in this important area is needed to test both models with clinical and non-clinical samples, and to examine causal relationships between the variables in experimental and longitudinal research designs.

In this study young people who reported more symptoms of depression generated selfimages that were more negative. This is consistent with the idea that negative self-evaluation may act as a cognitive bias and may also increase attention to negative self-referent information and rumination on negative information about the self (Nolen-Hoeksema, 2000). 
Thus, it is plausible that negative self-evaluation prompts the development of a depressive episode (Black \& Pössel, 2013). If so, this has implications for the assessment and prevention of depression in young people because negative self-evaluation may be an important early marker of vulnerability to depression. Similarly, those with a more positive self-evaluation may be more resilient to or protected from depression. Strategies which aim to increase attention to positive self-referent information (perceived as important to the individual), may boost accessibility to positive self-images and reduce negative biases (Dainer-Best, Shumake, \& Beevers, 2018). However, as indicated above these causal relationships cannot be inferred from our study. Strategies to improve positive self-imagery have been developed for use with adults (Holmes, Lang, \& Shah, 2009) and could be further tested in young people with negative self-concept and those who are at risk of depression..

In this study we used a method of assessing self-concept that used participants' own constructs and vocabulary; the Twenty Statement Task (TST). The TST has some important advantages over pre-populated, standardised methods of assessment. It is likely to elicit selfimages that are more salient and meaningful to young people and it offers greater flexibility. The method also does not rely on language or vocabulary that may become obsolete or is unfamiliar to young people. However, this method also has some short-comings that may be sensitive to cognitive and emotional development. In this study young people generated fewer than half of the self-images generated by adults (mean of 8.38 versus mean of 19.4 , Rees \& Nicholson, 2004). This may be for a number of reasons, including the possibility that young people have not yet fully developed or consolidated self-images and may have less experience of self-reflection and a more limited vocabulary. However, it may also reflect the fact that completing the TST is effortful and requires executive functioning skills of concentration and focused attention. Therefore, young people may have found it more difficult to generate multiple self-aspects, not because these did not yet exist but because the 
young people lacked fully developed meta-cognitive abilities, particularly those associated with executive functioning (Luna, 2009). This may be especially relevant for those with depression because deficits in executive functioning which are common amongst depressed young people (e.g. Fisk et al., 2019) make it even more difficult to generate specific selfimages. In contrast, methods of assessment that rely on participants endorsing pre-populated questionnaires make fewer demands on cognitive functioning and may be better at eliciting a wider range of self-aspects.

This potential difficulty with completing the TST may have had more impact on the assessment of self-complexity than self-evaluation. The index of self-evaluation is independent of the number of self-images generated. However, the number of distinct self 'aspects' that can be identified is directly limited by the number of self-images generated by the TST - it is not possible to have more self-aspects than the number of self-images generated. The executive demands of the TST and the limited number of self-images that young people generated may therefore have resulted in an under-estimate of participants' self-aspects. It may therefore be useful to use multiple methods to explore models of selfconcept.

It is possible that other factors not directly considered by this research may have influenced self-evaluation and depression symptoms reported by young people. For example, socially desirable responding may have occurred, i.e., young people may have described their 'best self' and therefore inhibited more negative self-images. However, adolescents with elevated symptoms of depression may have been less able to inhibit these more negative selfimages. This may have been exacerbated by adolescents completing the MFQ prior to the completion of the self-concept measure (TST). Thus, the MFQ may have induced a negative mood and influenced the valence of self-images (i.e., made negative self-images more accessible). Therefore, it is important that future research controls for this by 
counterbalanceing the order of measures or perhaps by assessing momentary mood before assessing self-evaluation. Other social and economic variable are known to be associated with depression in young people (Lorant et al., 2003). Thus in future, it may be important to assess for social-economic status (SES) and control for this when examining the association between depression symptoms and self image in young people.

\section{Conclusion}

Understanding how 'the self' develops and how it interacts with well-being and mental health during adolescence and in later life is an important area of clinical research. In this sample of young people aged 13-18 years there was a significant negative correlation between self-evaluation and severity of depression. These data support Beck's (1967) cognitive theory of depression. In contrast, the self-complexity model (Linville, 1985; 1987) was not supported i.e., there was no evidence that having more 'self-aspects' was protective against depression. However, there were limitations in the measurement of self-complexity in young people. The results of this study are novel and may have important implications for understanding how depression and self-concept develop during adolescence. They suggest that developing interventions to reduce negative self-concept and increase and consolidate positive self-concept, may be helpful in preventing and treating depression. To make meaningful progress that has potential for clinical value we need to examine the causal relationships between self-concept and depression in experimental and mechanistic research designs.

\section{Acknowledgements:}

The authors would like to thank all the staff and students within the participating schools. Also, special thanks to Thomas Mantell, Catherine Newell and Agni Omirou for their help coding data.

\section{Formatting of funding sources}


This research did not receive any specific grant from funding agencies in the public, commercial, or not-for-profit sectors. XX was supported by $\mathrm{PhD}$ studentship.

\section{Data Availability Statement}

Full data are not publicly available due to restricitions such as containing information that could compromise the privacy of research participants. However responses generated using the Twenty Statements Test are freely available in the UK Data Service ReShare Repository under 'XXX' (Author(s) details) at Website link. DOI: XX). 


\section{References}

Abela, J. R. Z., \& Véronneau-McArdle, M.-H. (2002). The relationship between self-complexity and depressive symptoms in third and seventh grade children: A short-term longitudinal study. Journal of Abnormal Child Psychology, 30(2), 155-166. doi:10.1023/a:1014705316224

Auerbach, R. P., Stanton, C. H., Proudfit, G. H., \& Pizzagalli, D. A. (2015). Self-referential processing in depressed adolescents: A high-density event-related potential study. Journal of Abnormal Psychology, 124(2), 233-245. doi:10.1037/abn0000023

Avenevoli, S., Swendsen, J., He, J.-P., Burstein, M., \& Merikangas, K. R. (2015). Major depression in the national comorbidity survey-adolescent supplement: Prevalence, correlates, and treatment. Journal of the American Academy of Child and Adolescent Psychiatry, 54(1), 3744. doi:10.1016/j.jaac.2014.10.010

Beck, A. T. (1967). Depression: Clinical, experimental, and theoretical aspects. Philadelphia: University of Pennsylvania Press.

Black, S. W., \& Pössel, P. (2013). The combined effects of self-referent information processing and ruminative responses on adolescent depression. Journal of Youth and Adolescence, 42(8), 1145-1154. doi:10.1007/s10964-012-9827-y

Brown, G., \& Rafaeli, E. (2007). Components of self-complexity as buffers for depressed mood. Journal of Cognitive Psychotherapy, 21(4), 310-333. doi:10.1891/088983907782638761

Cohen, J. R., Spiegler, K. M., Young, J. F., Hankin, B. L., \& Abela, J. R. (2014). Self-structures, negative events, and adolescent depression: Clarifying the role of self-complexity in a prospective, multiwire study. Journal of Early Adolescence, 34(6), 736-759. doi:10.1177/0272431613503217

Connolly, S. L., Abramson, L. Y., \& Alloy, L. B. (2016). Information processing biases concurrently and prospectively predict depressive symptoms in adolescents: Evidence from a self-referent encoding task. Cognition \& Emotion, 30(3), 550-560. doi:10.1080/02699931.2015.1010488 
Conway, M. A. (2005). Memory and the self. Journal of Memory and Language, 53(4), 594-628. doi:10.1016/j.jml.2005.08.005

Costello, E. J., \& Angold, A. (1988). Scales to assess child and adolescent depression: Checklists, screens and nets. Journal of the American Academy of Child and Adolescent Psychiatry, 27(6), 726-737. doi: 10.1097/00004583-198811000-00011

Dainer-Best, J., Shumake, J. D., \& Beevers, C. G. (2018). Positive imagery training increases positive self-referent cognition in depression. Behaviour Research and Therapy, 111, 72-83. doi: 10.1016/j.brat.2018.09.010

Damon, W., \& Hart, D. (1988). Self-understanding in childhood and adolescence. New York: Cambridge University Press.

Diamond, A. (2013). Executive Functions. Annual Review of Psychology, 64(1), 135-168. doi:10.1146/annurev-psych-113011-143750

Erikson, E. H. (1968). Identity: Youth and crisis. New York: W. W. Norton.

Evans, D. W. (1994). Self-complexity and its relation to development, symptomatology and selfperception during adolescence. Child Psychiatry and Human Development, 24(3), 173-182. doi:10.1007/BF02353194

Fergusson, D. M., Horwood, L. J., Ridder, E. M., \& Beautrais, A. L. (2005). Subthreshold depression in adolescence and mental health outcomes in adulthood. Arch Gen Psychiatry, 62(1), 66-72. doi:10.1001/archpsyc.62.1.66

Field, A. (2013). Discovering statistics using IBM SPSS statistics: and sex and drugs and rock 'n' roll (4th ed.). London: Sage.

Fischer, K. W. (1980). A theory of cognitive development: The control and construction of hierarchies of skills. Psychological Review, 87(6), 477-531. doi:10.1037/0033-295X.87.6.477

Holmes, E. A., Lang, T. J., \& Shah, D. M. (2009). Developing interpretation bias modification as a "cognitive vaccine" for depressed mood: imagining positive events makes you feel better than 
thinking about them verbally. Journal of Abnormal Psychology, 118(1), 76-88. doi:10.1037/a0012590

Jordan, A., \& Cole, D. A. (1996). Relation of depressive symptoms to the structure of selfknowledge in childhood. Journal of Abnormal Psychology, 105(4), 530-540. doi: 10.1037/0021-843X.105.4.530

Kaslow, N. J., Stark, K. D., Printz, B., Livingston, R., \& Ling Tsai, S. (1992). Cognitive triad inventory for children: Development and relation to depression and anxiety. Journal of Clinical Child Psychology, 21(4), 339-347. doi:10.1207/s15374424jccp2104_3

Kelvin, R. G., Goodyer, I. M., Teasdale, J. D., \& Brechin, D. (1999). Latent negative self-schema and high emotionality in well adolescents at risk for psychopathology. Journal of Child Psychology and Psychiatry, 40(6), 959-968, doi:10.1111/1469-7610.00513

Kuhn, H. M., \& McPartland, T. S. (1954). An empirical investigation of self-attitudes. American Sociological Review, 19(1), 68-76. doi:10.2307/2088175

Lemogne, C., Mayberg, H., Bergouignan, L., Volle, E., Delaveau, P., Lehéricy, S., . . Fossati, P. (2010). Self-referential processing and the prefrontal cortex over the course of depression: A pilot study. Journal of Affective Disorders, 124(1-2), 196-201. doi:10.1016/j.jad.2009.11.003

Linville, P. W. (1985). Self-Complexity and Affective Extremity: Don't Put All of Your Eggs in One Cognitive Basket. Social Cognition, 3(1), 94-120. doi:10.1521/soco.1985.3.1.94

Linville, P. W. (1987). Self-complexity as a cognitive buffer against stress-related illness and depression. Journal of Personality and Social Psychology, 52(4), 663-676. doi:10.1037/00223514.52.4.663

Luna, B. (2009). Developmental changes in cognitive control through adolescence. Advances in Child Development and Behavior, 37, 233-278. doi: 10.1016/S0065-2407(09)03706-9 
McConnell, A. R. (2011). The multiple self-aspects framework: Self-concept representation and its implications. Personality and Social Psychology Review, 15(1), 3-27. doi:10.1177/1088868310371101

Morgan, H. J., \& Janoff-Bulman, R. (1994). Positive and negative self-complexity: patterns of adjustment following traumatic versus non-traumatic life experiences. Journal of Social and Clinical Psychology, 13(1), 63-85. doi: 10.1521/jscp.1994.13.1.63

Neisser, U. (1991). Two perceptually given aspects of the self and their development. Developmental Review, 11(3), 197-209. doi: 10.1016/0273-2297(91)90009-D

Orchard, F., Pass, L., Marshall, T., \& Reynolds, S. (2017). Clinical characteristics of adolescents referred for treatment of depressive disorders. Child and Adolescent Mental Health. 22(2), 61-68. doi:10.1111/camh.12178

Orchard, F., \& Reynolds, S. (2018). The combined influence of cognitions in adolescent depression: Biases of interpretation, self-evaluation, and memory. British Journal of Clinical Psychology, 57(4), 420-435. doi:10.1111/bjc. 12184

Orth, U., Robins, R. W., Widaman, K. F., \& Conger, R. D. (2014). Is low self-esteem a risk factor for depression? Findings from a longitudinal study of Mexican-origin youth. Developmental Psychology, 50(2), 622-633. doi:10.1037/a0033817

Oyserman, D., Elmore, K., \& Smith, G. (2012). Self, self-concept and identity. In M. R. Leary \& J. P. Tangney (Eds.), Handbook of Self and Identity (pp. 69-104). New York: Guilford Press.

Rafaeli-Mor, E., Gotlibb, I. H., \& Revelle, W. (1999). The meaning and measurement of selfcomplexity. Personality and Individual Differences, 27(1), 341-356. doi: 10.1016/S01918869(98)00247-5

Rafaeli-Mora, E., \& Steinberg, J. (2002). Self-complexity and well-being: A review and research synthesis. Personality and Social Psychology Review, 6(1), 31-58. doi:10.1207/S15327957PSPR0601_2 
Rathbone, C. J., Moulin, C. J., \& Conway, M. A. (2008). Self-centered memories: the reminiscence bump and the self. Memory \& Cognition, 36(8), 1403-1414. doi:10.3758/MC.36.8.1403

Rees, A., \& Nicholson, N. (2004). The twenty statements test. In C. Cassell \& G. Symon (Eds.), Essential guide to qualitative methods in organizational research (pp. 86-89). London: SAGE Publications.

Singer, J. A., \& Salovey, A. P. (1993). The remembered self. New York: The Free Press.

Stanley, I. H., Hom, M. A., Luby, J. L., Joshi, P. T., Wagner, K. D., Emslie, G. J., . . Joiner, T. E. (2017). Comorbid sleep disorders and suicide risk among children and adolescents with bipolar disorder. Journal of Psychiatric Research, 95, 54-59. doi:10.1016/j.jpsychires.2017.07.027

Steiger, A. E., Allemand, M., Robins, R. W., \& Fend, H. A. (2014). Low and decreasing self-esteem during adolescence predict adult depression two decades later. Journal of Personality and Social Psychology, 106(2), 325-338. doi:10.1037/a0035133

Wood, A., Kroll, L., Moore, A., \& Harrington, R. (1995). Properties of the mood and feelings questionnaire in adolescent psychiatric outpatients: a research note. The Journal of Child Psychology and Psychiatry, 36. doi:10.1111/j.1469-7610.1995.tb01828.x

Zubrick, S. R., Hafekost, J., Johnson, S. E., Sawyer, M. G., Patton, G., \& Lawrence, D. (2017). The continuity and duration of depression and its relationship to non-suicidal self-harm and suicidal ideation and behavior in adolescents 12-17. Journal of Affective Disorders, 220, 4956. doi:10.1016/j.jad.2017.05.050 
Table 1. Inter-correlations of all variables included in the analysis $(\mathrm{N}=769)$.

\begin{tabular}{lccccc}
\hline Measure & 1 & 2 & 3 & 4 & 5 \\
\hline 1. Depression scores & - & $.27^{*}$ & -.02 & $.11^{* *}$ & $-.54^{* *}$ \\
2. Gender & - & - & .07 & $.16^{* *}$ & $-.17^{* *}$ \\
3. Age & - & - & - & -.01 & .05 \\
4. Self-complexity & - & - & - & - & $-.17^{* *}$ \\
5. Self-Valence Index (SVI) & - & - & - & - & -
\end{tabular}

Note.

$* p<.01, * * p<.001$ 


\begin{tabular}{|c|c|c|c|c|c|}
\hline & \multirow[b]{2}{*}{$\Delta \mathrm{R}^{2}$} & \multirow[b]{2}{*}{$b(\mathrm{SE})$} & \multirow[b]{2}{*}{$\beta$} & \multicolumn{2}{|c|}{$95 \% \mathrm{BCa} \mathrm{Cl}$ for odds ratic } \\
\hline & & & & Lower & Upper \\
\hline Step 1 & $.07 * *$ & & & & \\
\hline Constant & & $13.33(.60)$ & & 12.25 & 14.56 \\
\hline Gender $(0=$ male $)$ & & $6.852(.91)$ & $.27 * *$ & 5.30 & 8.34 \\
\hline Step 2 & $.25^{* *}$ & & & & \\
\hline Constant & & $27.45(1.14)$ & & 25.35 & 29.85 \\
\hline Gender & & $4.56(.78)$ & $.18 * *$ & 3.11 & 5.88 \\
\hline Self-Valence Index (SVI) & & $-9.55(.62)$ & $-.51 * *$ & -10.85 & -8.43 \\
\hline Step 3 & .00 & & & & \\
\hline Constant & & $27.84(1.33)$ & & 25.19 & 30.58 \\
\hline Gender & & $4.61(.79)$ & $.18 * *$ & 3.10 & 5.99 \\
\hline Self-Valence Index (SVI) & & $-9.59(.62)$ & $-.51 * *$ & -10.90 & -8.41 \\
\hline Self-complexity & & $-.12(.25)$ & -.02 & -.63 & .39 \\
\hline
\end{tabular}

Note. $* p<.05, * * p=.001$

Table 2. Hierarchical multiple regression results: Predictors of depression symptoms 